Artigo Original

\title{
O programa de reabilitaçáo profissional do INSS e a reinserçáo do trabalhador no mercado de trabalho ${ }^{1}$
}

\section{The INSS professional rehabilitation program and the reinsertion of workers into the job market}

\author{
Geovana de Souza Henrique dos Santos ${ }^{a}$ (D), Roseli Esquerdo Lopes ${ }^{a}$ (D) \\ ${ }^{a}$ Universidade Federal de São Carlos - UFSCar, São Carlos, SP, Brasil.
}

Como citar: Santos, G. S. H., \& Lopes, R. E. (2021). O programa de reabilitação profissional do INSS e a reinserção do trabalhador no mercado de trabalho. Cadernos Brasileiros de Terapia Ocupacional, 29, e2100. https://doi.org/10.1590/2526-8910.ctoAO2100

\begin{abstract}
$\underline{\text { Resumo }}$
Introduçáo: No Brasil, a assistência pública voltada aos trabalhadores acometidos por doenças ou acidentes, incapazes de exercerem sua profissão, mas com potencial laborativo residual, é prestada pelo Instituto Nacional do Seguro Social (INSS), por meio do Programa de Reabilitação Profissional (PRP). Objetivo: Compreender a contribuiçáo do PRP na reinserçáo do trabalhador no mercado de trabalho. Método: Trata-se de um estudo de caso, documental, transversal e descritivo, que teve como fonte de dados 592 prontuários de trabalhadores encaminhados ao PRP de uma Agência do INSS da região Sudeste do Brasil, no período de 2007 a 2012, dos quais foram extraídos dados sociodemográficos, acadêmicos e profissionais, além de entrevistas com oito usuários reabilitados. Resultados: Os resultados apontaram que, dentre os segurados encaminhados ao Programa, 48,5\% foram elegíveis, 34\% considerados reabilitados e, destes, 49,02\% estavam empregados. Os entrevistados não apontaram relaçáo direta entre o PRP e sua reinserção no mercado, mas afirmaram que os recursos utilizados foram importantes para conquistarem, senão um emprego, ao menos reconhecimento pessoal e profissional. Apesar da taxa de empregabilidade dos trabalhadores reabilitados ser satisfatória em comparação com aqueles encontrados em estudos de países desenvolvidos e com sociedades menos desiguais, esse aparato ainda náo se tornou um aliado efetivo do trabalhador brasileiro. Conclusáo: É essencial que os profissionais do INSS e
\end{abstract}

\footnotetext{
${ }^{1}$ Este texto é parte da dissertação de mestrado intitulada "O Programa de Reabilitação Profissional do Instituto Nacional do Seguro Social e a reinserção do trabalhador no mercado de trabalho: um estudo de caso", desenvolvida junto à linha de pesquisa "Redes Sociais e Vulnerabilidades", do Programa de Pós-Graduação em Terapia Ocupacional da Universidade Federal de São Carlos.

*A pesquisa já foi apresentada no XIV Congresso Brasileiro de Terapia Ocupacional.

**O artigo é original, não se encontra sob análise em qualquer outro veículo de comunicação científica e não foi publicado em outro periódico científico de forma total ou parcial.
} 
reabilitados tenham uma postura mais ativa no processo reabilitatório. Deve-se considerar a promoção de açóes intersetoriais que busquem articular as políticas públicas relativas à área e que abarquem a complexidade do processo de retorno ao trabalho.

Palavras-chave: Reabilitação Profissional, Previdência Social, Instituto Nacional do Seguro Social, Readaptação ao Emprego, Retorno ao Trabalho.

\section{Abstract}

Introduction: In Brazil, public assistance to workers affected by diseases or accidents, unable to practice their profession, but with residual work potential, is provided by the National Social Security Institute (INSS), through the Professional Rehabilitation Program (PRP). Objective: To understand the PRP's contribution to the reinsertion of the worker into the labor market. Method: It is a case study, documentary, cross-sectional and descriptive, which had as a data source 592 medical records of workers referred to the PRP of an INSS Agency of the Southeast region of Brazil, from 2007 to 2012, from which they were extracted sociodemographic, academic and professional data, as well as interviews with eight rehabilitated users. Results: The results showed that $48.5 \%$ of the insured persons were eligible, 34\% considered rehabilitated and 49.02\% were employed. The respondents did not point out a direct relationship between the PRP and their reinsertion in the market but stated that the resources used were important to achieve, if not a job, at least personal and professional recognition. Although the employability rate of the rehabilitated workers is satisfactory compared to those found in studies of developed countries and with less unequal societies, this apparatus has not yet become an effective Brazilian worker ally. Conclusion: It is essential that the INSS and rehabilitated professionals have a more active stance in the rehabilitation process. The promotion of intersectoral actions to articulate the public policies related to the area and that encompass the complexity of the process of return to work should be considered.

Keywords: Rehabilitation, Vocational, Social Security, Instituto Nacional do Seguro Social, Employment, Supported, Return to Work.

\section{Introduçáo}

Trabalho, ato de produção e reprodução da vida humana; é por meio dele que o homem se torna um ser social, condição para a sua existência, e se distingue das demais formas não humanas (Antunes, 2011). Para Castel (2010, p. 578), “[...] o trabalho continua sendo uma referência não só economicamente, mas também psicologicamente, culturalmente e simbolicamente dominante, como provam as reaçôes dos que não o têm”.

$\mathrm{Na}$ sociedade capitalista, a força de trabalho se tornou a única propriedade de grande parte dos trabalhadores, assim, a saúde deles se transformou numa qualidade que, em vez de atender às suas necessidades, atenderia aos interesses do capital, por possibilitar maior produtividade e consumo. Quanto maior o número de trabalhadores, de fato, 
produtivos, maior será a quantidade do exército de reserva, que se submeterá a empregos ociosos e precários (Soares, 1991).

O progresso técnico e a acumulação do capital criaram e ampliaram essa reserva de trabalhadores que, cronicamente afastada do sistema produtivo, participa do processo produtivo somente em picos de acumulação. Assim, agrega os indivíduos doentes, com deficiência, vítimas da indústria, com idade considerada avançada e outros que não correspondem ao perfil cumulativo (Soares, 1991).

A emergência de algum tipo de proteção social aos trabalhadores, visando minimizar as situaçóes de vulnerabilidade e regular condições de trabalho, vincula-se à industrialização, posta como uma autodefesa do trabalho perante o capital (Fleury, 1994). O desenvolvimento do sistema de proteçáo social brasileiro teve como base a formação histórica do país, advinda de experiência colonial e escravocrata. Os trabalhadores, historicamente, tornaram-se os responsáveis por sua sobrevivência e o acesso aos bens e serviços sociais ficou marcado pela desigualdade, heterogeneidade e fragmentação (Yazbek, 2012).

O seguro social, no Brasil, que protege a maioria dos trabalhadores inserida no mercado de trabalho do setor privado é administrado pelo Estado, embora tenha surgido em decorrência da iniciativa de trabalhadores (Batich, 2004; Yazbek, 2012). A Previdência Social, por meio do Instituto Nacional do Seguro Social (INSS), disponibiliza benefícios aos contribuintes, que incluem aposentadorias, pensôes, benefício de prestação continuada, além de outros esporádicos, como auxílio-natalidade, auxílio-reclusão, auxílio-doença, objetivando garantir a reprodução do trabalhador e de sua família em situaçóes de risco, sejam elas velhice, acidente ou doença (Soares, 2001; Fleury, 1994).

Outro benefício é a reabilitação profissional, instituída em 1943 pelas Caixas de Aposentadorias e Pensões e Institutos de Aposentadorias e Pensóes, embrióes do sistema previdenciário (Soares, 1991). O termo foi consolidado em 1960, visto como uma “[...] resposta pública à questão da incapacidade” (Takahashi \& Iguti, 2008, p. 2662). É a assistência (re)educativa e de (re)adaptação profissional que visa proporcionar aos segurados, “[...] incapacitados parcial ou totalmente para o trabalho, em caráter obrigatório, independentemente de carência, e às pessoas com deficiência, os meios indicados para o reingresso no mercado de trabalho e no contexto em que vivem" (Brasil, 2010).

O encaminhamento ao Programa de Reabilitação Profissional (PRP) do INSS é realizado pela perícia médica do Instituto e o atendimento é feito pela equipe do PRP da Agência da Previdência Social, preferencialmente multidisciplinar, composta por médicos peritos e profissionais de serviço social, psicologia, terapia ocupacional, sociologia, fisioterapia, ou áreas afins ao processo (Brasil, 2010). Após a constatação, pela equipe, da elegibilidade do segurado para o PRP, ele é encaminhado para realizar treinamento, curso ou protetização. A empresa de vínculo é contatada, solicitando-se sua readaptaçáo, e o encaminhamento para cursos ou treinamentos na comunidade ocorre com o usuário sem vínculo empregatício, com outra forma de filiação ao Instituto ou caso seja inviável a troca de função na empresa (Instituto Nacional do Seguro Social, 2011).

O processo reabilitatório termina quando o usuário conclui, satisfatoriamente, o treinamento na empresa de vínculo, o curso profissionalizante ou, ainda, mediante a 
entrega e adaptação à prótese. Emite-se um certificado homologando tal processo, o benefício previdenciário é cessado, considerando-se o trabalhador reabilitado e em condiçóes de retornar ao mercado de trabalho. O certificado é individual e indica a função para a qual o reabilitado foi capacitado profissionalmente, sem prejuízo do exercício de outra para a qual se julgue capacitado (Brasil, 2010; Instituto Nacional do Seguro Social, 2011). Pode ser utilizado pelo trabalhador, de acordo com o seu interesse, em qualquer empresa do país, independentemente do cargo, para concorrer a vagas especiais, reservadas às pessoas com deficiência ou reabilitadas pelo INSS.

Com vistas a alguma garantia de inserção no mercado de trabalho, a legislação prevê que empresas com 100 ou mais empregados preencham de $2 \%$ a $5 \%$ de seus cargos com pessoas com deficiência ou reabilitadas pelo INSS, conhecida como Lei de Cotas, com a seguinte distribuição: de 100 a 200 empregados, 2\%, de 201 a 500, 3\%, de 501 a $1.000,4 \%$ e, acima de 1.001, 5\% (Brasil, 1991).

Nesse contexto, insere-se a pesquisa aqui apresentada, que teve como objetivo geral compreender a contribuição do PRP do INSS na reinserção do trabalhador brasileiro no mercado de trabalho. Seus objetivos específicos foram: identificar o perfil da população encaminhada ao PRP de uma Agência da Previdência Social (APS) da região Sudeste do Brasil, entre 2007 e 2012; traçar o perfil profissional dos usuários elegíveis para o PRP; investigar os meios utilizados pelo PRP para reinserir o trabalhador no mercado de trabalho e caracterizar, na visão dos reabilitados, como o PRP interferiu em sua reinserção no mercado.

\section{Consideraçóes das autoras}

Este trabalho foi finalizado em 2015. Assim, neste momento, cabe pontuar a permanência de sua relevância em 2020, justificando sua divulgação.

O Serviço de Reabilitação Profissional continua sendo executado pelo INSS, mantendo sua centralidade no processo de reinserção no mercado de trabalho de trabalhadores contribuintes que se encontram incapacitados para o exercício de suas profissôes, campo de atuação do terapeuta ocupacional e outros profissionais de áreas afins à saúde do trabalhador.

Nos últimos quatro anos, houve um esvaziamento do Serviço, que envolve vários fatores, com destaque para alguns que são observados diariamente na execução das açóes, a saber: 1- a Reforma Trabalhista, ocorrida em 2016, que agravou as condições de trabalho, deixando os trabalhadores mais vulneráveis; 2 - mudanças na operacionalização do PRP (Brasil, 2018); 3- repercussões políticas na gestão da autarquia, desde o impeachment, em agosto de 2016, e dos governos federais que se seguiram até aqui, colocando o INSS em destaque por sua [in] eficiência na restrição do acesso às aposentadorias e pensóes requeridas por trabalhadores brasileiros e suas famílias, diante das ameaças concretizadas pela Reforma de Previdência de 2019, tema que permanece em diversas mídias, ou, ainda, nesse âmbito, por não priorizar a execuçáo de seus serviços em função de diretrizes que têm como foco a economia de gastos, por exemplo, com a manutenção de benefícios por incapacidade; 4- o desafio diário de fomentar um diálogo com os Peritos Médicos Federais, que deixaram de pertencer ao quadro de servidores do INSS em 2019, e são o elo inicial para a chegada do trabalhador ao PRP e também para 
a manutenção deste no serviço; e, por fim, 5- a pandemia de COVID-19, no ano de 2020, com desemprego em massa e agravos sem precedentes, ainda em curso.

Com dificuldades em vários níveis, variando conforme a região do país onde é executada a reabilitaçáo profissional do segurado, continua desafiador o processo de reingresso dos reabilitandos no mercado de trabalho e no contexto em que vivem. Mesmo não sendo o foco deste trabalho, tem-se a certeza de que as consideraçóes empíricas descritas no último parágrafo, embora não tenham sido fruto de investigação metódica, oferecem os aportes necessários para a defesa da pertinência e relevância das discussóes e análises trazidas ao longo deste artigo, justamente em seu recorte de dados, que, apesar do tempo, refletem uma gravidade que se adensa.

Entende-se que o estudo apresentado, mesmo com limites em seu delineamento histórico, traz contribuições para os sujeitos envolvidos no processo de reabilitação profissional. Certamente, há necessidade de atualização do tema, com novas pesquisas que abarquem o momento atual e as diretrizes vigentes, não obstante, conhecer a dinâmica passada pode embasar uma análise integral e com perspectivas mais realistas acerca do Serviço de Reabilitação Profissional executado pelo INSS, no Brasil de hoje.

\section{Métodos}

\section{Levantamento da literatura na área, tipo de estudo e abordagem empírica}

Foram consultadas, entre maio de 2013 e maio de 2014, as bases de dados Literatura Latino-Americana e do Caribe em Ciências da Saúde, a Scientific Electronic Library Online, o Banco de Teses e Dissertações da Coordenação de Aperfeiçoamento de Pessoas de Nível Superior e os principais periódicos brasileiros da área de terapia ocupacional: Cadernos de Terapia Ocupacional da Universidade Federal de São Carlos e a Revista de Terapia Ocupacional da Universidade de São Paulo. Foi utilizado o termo "Programa de Reabilitação Profissional" associado a "INSS" e a "Instituto Nacional do Seguro Social”, que levou à seleção de 26 artigos brasileiros. A busca foi voltada para a literatura nacional, dado o foco específico da pesquisa no contexto brasileiro, além de livros correlatos, tendo sido agregados, posteriormente, alguns trabalhos estrangeiros significativos.

Trata-se de um estudo transversal, do tipo descritivo, no qual a coleta de dados dos processos dos segurados encaminhados ao PRP ocorreu num momento único, correlacionadas variáveis com o objeto do estudo e interpretadas segundo a literatura. Esse tipo de pesquisa visa a descrever variáveis e a analisar a sua incidência e inter-relação em um dado momento, além de situar e proporcionar uma visão sobre o fenômeno estudado (Sampieri et al., 2006). Foi também uma pesquisa documental, que destaca como fonte de dados documentos, escritos ou não, constituindo o que se denomina de "fontes primárias". Fontes estas que podem ser recolhidas no momento em que o fato ou fenômeno ocorre, ou depois e que ainda não receberam tratamento analítico (Lakatos \& Marconi, 2002). A fonte usada foram os prontuários físicos dos trabalhadores encaminhados ao PRP; eram processos escritos contendo a descrição das avaliaçôes e atendimentos já encerrados e arquivados. Ainda, a pesquisa se deu com base em um estudo de caso, por ter sido enfocada uma única agência do INSS. 


\section{Local do estudo e procedimentos éticos}

O universo desta pesquisa foi o INSS, com enfoque no PRP de uma agência da Previdência Social, situada no interior da região Sudeste do Brasil, uma das regióes mais desenvolvidas do país. A cidade abarcada pela Agência estudada, de acordo com o censo demográfico de 2010, tem uma população estimada de 318.813 habitantes e, em 2012, ficou em quarto lugar quanto à sua contribuição ao Produto Interno Bruto do Agronegócio brasileiro. A economia é diversificada, porém, sua base é composta pelo setor de Serviços, responsável pela maior movimentação financeira, seguido pela Indústria (Instituto Brasileiro de Geografia e Estatística, 2014). Como é possível perceber, trata-se de uma cidade com recursos econômicos e humanos consideráveis.

O estudo foi autorizado pelo gerente da instituição e aprovado pelo Comitê de Ética em Pesquisa apropriado, sob o Parecer 386.931/2013. Os sujeitos foram convidados a colaborar com o estudo por meio da concessão de uma entrevista e assinaram o Termo de Consentimento Livre Esclarecido. Foi feito o compromisso do sigilo em relação aos nomes dos sujeitos envolvidos e do local da sede da agência pesquisada. $\mathrm{O}$ atendimento no PRP dessa agência era feito por uma equipe composta por três profissionais, sendo dois terapeutas ocupacionais e um médico. Houve a apresentação dos resultados para a equipe, além da devolutiva aos demais que concordaram em colaborar.

\section{Escolha dos sujeitos da pesquisa}

O estudo abrangeu os prontuários de trabalhadores encaminhados ao PRP do INSS dessa agência no período de 2007, ano em que se inicia o arquivo ativo do Programa, a 2012, uma vez que a coleta de dados teve início no ano de 2013. Nesse período, foram encaminhadas ao PRP da agência 676 pessoas e, após a varredura manual de todos os prontuários, foram selecionados 592. Como critério de inclusão, definiu-se os processos encerrados até 31/12/2012 e, de exclusão, os processos de usuários que ainda estavam em Programa. Foram compostos quatro grupos de dados, porém, neste artigo, serão abarcados apenas três, uma vez que um deles, que abrangia 264 prontuários de trabalhadores não elegíveis para o PRP, buscando quais os motivos dessa inelegibilidade, foi tema de outra publicação ${ }^{2}$.

O primeiro grupo abarcou todos os 592 processos; desses, constatou-se que 300 pessoas foram consideradas elegíveis para o PRP, das quais foi composto o segundo grupo, subdividido em dois: a) 198 usuários que não concluíram o PRP conforme o previsto pela instituição; b) 102 usuários que concluíram o PRP de acordo com o previsto. $\mathrm{O}$ terceiro grupo abarcou oito usuários reabilitados, convidados a colaborar com a pesquisa por meio da concessão de uma entrevista; das 14 pessoas contatadas inicialmente por telefone, oito concordaram em participar. Elas foram selecionadas a partir do tipo de recurso usado no processo reabilitatório, uma vez que uma hipótese presente era que o tipo de recurso influenciaria na reinserção do trabalhador. Definiuse por entrevistar duas pessoas reabilitadas por meio de cada um dos recursos, sendo

\footnotetext{
${ }^{2} \mathrm{O}$ artigo apontou os motivos para a não inclusão dos trabalhadores no PRP: "Possibilidade de Retorno ao Trabalho", em 46,97\%; "Impossibilidade de Retorno ao Trabalho", em 29,55\%; "Potencial Laborativo Indefinido", totalizando 15,15\%; "Inelegível Temporário", em 4,55\%; "Transferência do Benefício", em 2,27\%; "Trabalhador Autorreabilitando", no total de 1,14\%; e "Sem Justificativa”, em 0,38\% (Santos \& Lopes, 2015).
} 
estes: 1) oferta de cursos: a) de qualificação e b) técnico; 2) protetização; e 3) realização de treinamento/readaptação na empresa de vínculo. Outro critério utilizado foi a data de desligamento do PRP, priorizando-se pessoas reabilitadas mais recentemente, pois elas poderiam se recordar com maior facilidade de suas vivências.

\section{Recursos utilizados para a coleta de dados}

Elaborou-se um único instrumento para a coleta dos dados dos prontuários do primeiro e do segundo grupos, a fim de padronizá-los. Esse instrumento foi dividido em duas partes: I- aplicada aos prontuários de todos os usuários encaminhados ao Programa; II- aplicada aos prontuários dos usuários elegíveis para o Programa, dividida em duas categorias, sendo a primeira aplicada aos usuários que não concluíram o Programa conforme o preconizado, e a segunda aos usuários considerados reabilitados pela instituição. A parte I abrangeu dados sociodemográficos, acadêmicos e profissionais, sobre o histórico de afastamento do trabalho e a conclusão da equipe do PRP acerca da avaliação do potencial laborativo. Sobre a profissão dos usuários, como foram muito diversas, decidiu-se por agrupá-las utilizando-se a Classificação Nacional de Atividades Econômicas (Brasil, 2014). Os diagnósticos foram agrupados pela Classificação Internacional de Doenças e Problemas Relacionados à Saúde (CID10).

$\mathrm{Na}$ parte II, na primeira categoria, foram verificados os recursos utilizados no processo de reabilitação dos trabalhadores e os motivos que levaram a não conclusão do PRP. Na segunda categoria, depois de observados os recursos utilizados para reabilitar o trabalhador, averiguou-se a situação empregatícia dos reabilitados, obtida entre os dias 5 e 6 de março de 2014, e extraída dos sistemas operacionais do INSS: o Cadastro Nacional de Informaçóes Sociais e o Sistema de Administração de Benefícios por Incapacidade. Verificou-se, respectivamente, se o trabalhador estava empregado ou em benefício previdenciário. Já para as entrevistas com os reabilitados, que compuseram o terceiro grupo, foi elaborado um roteiro prévio, semiestruturado, abrangendo unidades temáticas que levassem à compreensão sobre a contribuição do PRP na reinserção do trabalhador no mercado de trabalho.

\section{Análise dos dados}

$\mathrm{Na}$ análise dos dados, trabalhou-se com uma abordagem mista, quantitativa e qualitativa, buscando evidenciar padróes e refinar as questóes da pesquisa num processo de interpretação dos dados, usando dados numéricos, concomitante a uma abordagem compreensiva e crítica dos resultados. A discussão foi subdividida entre os dados advindos dos prontuários, basicamente estatísticos, e dos relatos das entrevistas, que são mais descritivos e qualitativos. As informações dos prontuários foram tabuladas, tratadas estatisticamente e, quando necessário, criadas categorias temáticas para agrupá-las. As entrevistas, realizadas em 2014, no local de escolha dos sujeitos, gravadas em áudio totalizando 4 horas e 31 minutos, transcritas em 101 páginas, foram lidas exaustivamente, destacando-se os pontos centrais e formando categorias, sendo que dentro de cada uma as respostas foram agrupadas conforme o recurso utilizado no processo reabilitatório. 


\section{Resultados}

\section{Perfil dos usuários encaminhados ao Programa de Reabilitaçáo Profissional e recursos utilizados no processo reabilita tório}

Os dados extraídos dos prontuários, das Avalições do Potencial Laborativo (APL), apontaram que $76,52 \%$ dos trabalhadores encaminhados ao PRP eram do sexo masculino, $61,15 \%$ tinham uma idade entre 30 a 44 anos, $62 \%$ se declararam casados ou em uniáo estável, cerca de $15 \%$ apresentavam algum tipo de deficiência e $42 \%$ não concluiu o Ensino Fundamental. As profissões predominantes foram de motoristas de caminhão e estivadores, na área de "Transporte, armazenagem e correio" (24,83\%), seguidas de operadores de linhas de produção e serviços gerais, na "Indústria de transformação" (18,24\%).

Dentre as pessoas encaminhadas ao PRP, 74,5\% estavam filiadas ao INSS como empregadas, seguidas por $15,37 \%$ que estavam desempregadas. Ainda, $22 \%$ recebiam o benefício de auxílio-doença acidentário, relacionado a doenças com nexo causal com o trabalho. Os diagnósticos indicaram que 33,11\% possuíam lesão por causa externa, códigos S e T da CID 10; 32,43\% foram acometidos por doenças do sistema osteomuscular e do tecido conjuntivo, código M; e 10,81\% sofriam com doenças do sistema nervoso, código G. Também foi verificado que $25 \%$ das pessoas estavam afastadas do trabalho entre um e dois anos; $18,6 \%$ até seis meses; $17 \%$ de seis meses a um ano. O valor do benefício previdenciário, em $43,92 \%$ dos casos, correspondia ao valor de um a dois salários mínimos, seguido por 20,95\% com até um salário. Nos pareceres emitidos pela equipe que realizou o atendimento, menos da metade dos trabalhadores, $48,48 \%$, foi eleita para o PRP; $2,2 \%$ foram encaminhados apenas para a protetização; $17,06 \%$ foram avaliados como não necessitando do PRP e em 13,34\% dos casos foi sugerida a aposentadoria por invalidez, conforme a Figura 1.

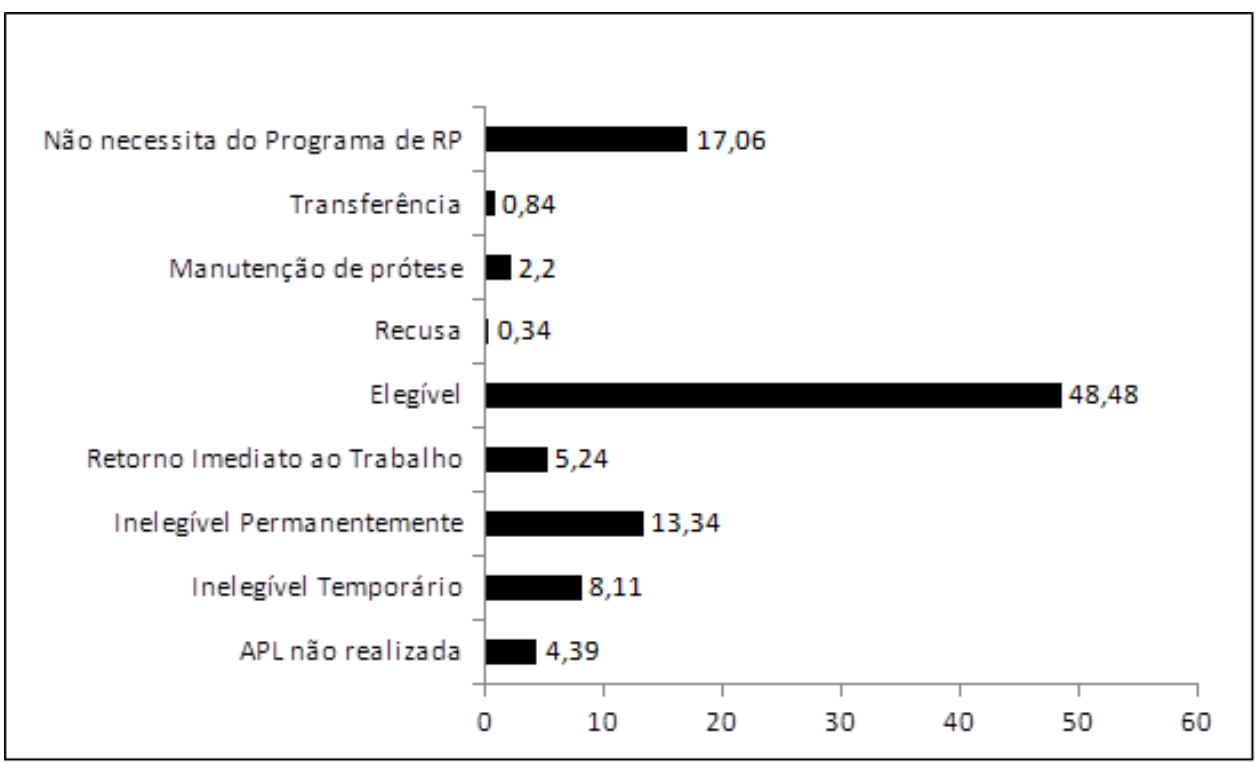

Figura 1. Pareceres da equipe baseados nos códigos previdenciários em \%. 
Com 46,34\% dos usuários eleitos para o PRP não foi utilizado nenhum recurso e, apesar de não terem sido pesquisados os motivos para tanto, referiam-se aos casos em que o trabalhador não concluiu o PRP, conforme o preconizado. Para 53,66\%, foram utilizados três tipos de recursos, que poderiam ser também associados: protetização; oferta de cursos, de qualificação e técnicos; e realização de treinamentos na empresa de vínculo do usuário.

No caso da protetização, 5,33\% das pessoas elegíveis receberam próteses e, destas, $50 \%$ receberam prótese de membro inferior, $43,75 \%$ prótese auditiva e $6,25 \%$ prótese de membro superior. Quanto aos cursos, foram oferecidos a 23,33\% dos usuários, e $25 \%$ realizaram treinamento em nova função na empresa de vínculo. Destaca-se que a maioria das empresas, 41,67\%, não ofereceu uma nova função ao trabalhador assistido, observando-se, todavia, que em $15,33 \%$ dos casos não havia a possibilidade da oferta de treinamento na empresa de vínculo, pois o usuário não era filiado ao INSS como empregado, em 4,67\% dos casos, a equipe não solicitou readaptação e $4 \%$ das empresas não foram localizadas.

\section{Perfil profissional dos usuários que passaram pelo Programa de Reabilitaçáo \\ Profissional}

Os usuários considerados reabilitados pelo INSS totalizaram 34\% dos elegíveis (48,48\%); desses, 49,02\% estavam empregados ou trabalhavam autonomamente, $26,47 \%$ estavam "Sem vínculo", $15,68 \%$ se encontravam afastados do trabalho, recebendo o benefício previdenciário, e $8,82 \%$ foram aposentados por invalidez, por decisão do INSS ou judicial (Figura 2).

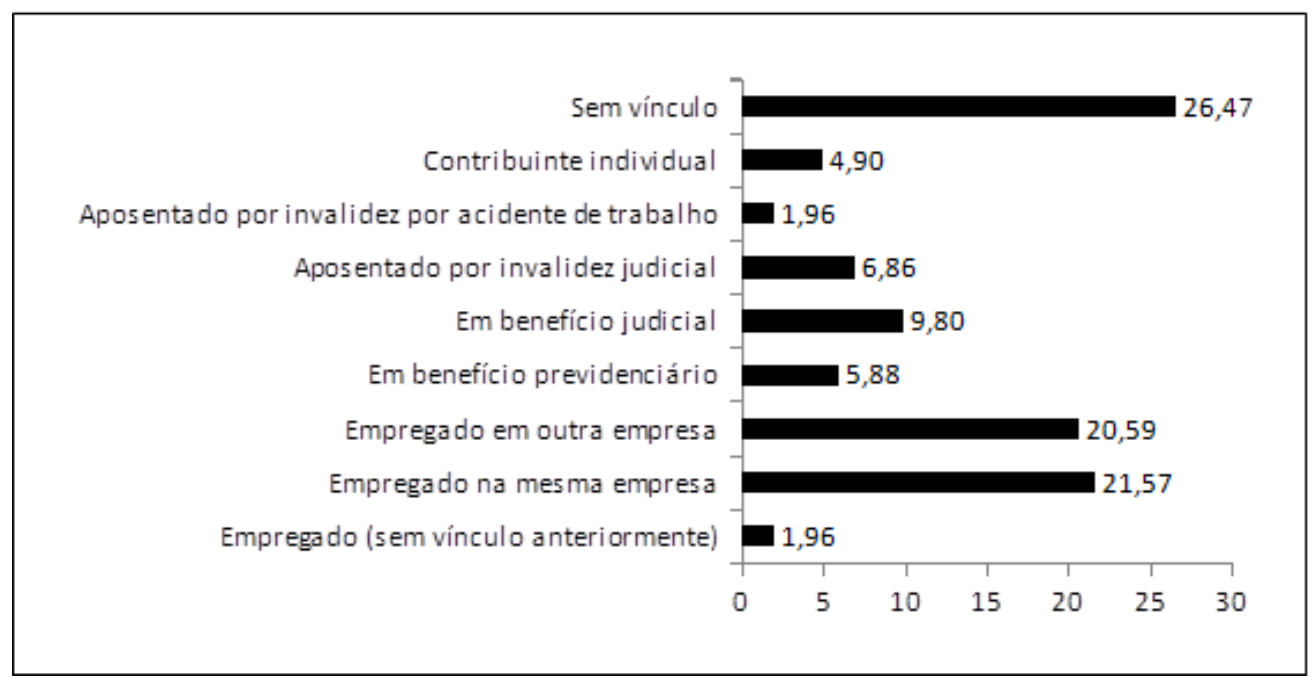

Figura 2. Situação empregatícia dos trabalhadores reabilitados em \%.

No que se refere aos $66 \%$ das pessoas que não concluíram o PRP segundo o preconizado pelo INSS, foram elaboradas categorias para reunir as principais justificativas redigidas pela equipe nos pareceres finais dos prontuários, sendo elas: "Impossibilidade de Retorno ao Trabalho", "Possibilidade de Retorno ao Trabalho", 
"Não Cumprimento do Programa”, e "Outras". Esta última agregou as justificativas com menor incidência, que são: "Intercorrência Médica", "Solicitação de Alta", "Transferência do Benefício", "Desinteresse no Programa" e "Impossibilidade de Contratação de Curso".

\section{Contribuiçóes do Programa de Reabilitaçáo Profissional na visáo de usuários reabilitados}

\section{História de vida laborativa e percurso no PRP}

O Sujeito 1 (S1) era mototaxista e sofreu uma amputação de membro inferior devido a um acidente de trabalho; foi elegível para o PRP apenas para protetização. O Sujeito 2 (S2) trabalhou 29 anos para a empresa de vínculo, era motorista de caminhão, desenvolveu um transtorno de pânico e se afastou do trabalho. No PRP, realizou treinamento na empresa e foi readaptado na função de serviços gerais, em um viveiro de plantas. Já o Sujeito 3 (S3), era trabalhador avulso há 15 anos, estivador, e tinha Ensino Fundamental incompleto. Sofreu acidente de trabalho, que levou a deslocamentos discais intervertebrais; realizou curso de sua escolha no PRP, de Eletricista Predial, com duração de seis meses e foi considerado reabilitado. A quarta entrevistada, Sujeito 4 (S4), era faxineira, desenvolveu arritmia cardíaca, o que a impedia de realizar suas atividades laborativas. Foi afastada do trabalho pelo INSS e durante esse período elevou a escolaridade e ingressou no curso Técnico em Farmácia, numa Universidade Pública. Encaminhada e mantida no PRP até a conclusão do curso.

O Sujeito 5 (S5), professor, pós-graduado, sofreu amputação de MI devido a uma trombose decorrente de uma doença vascular, mantido no PRP para a protetização. $\mathrm{O}$ Sujeito 6 (S6), operador de produção, desenvolveu dorsalgia devido ao trabalho, o que lhe garantia legalmente estabilidade de um ano no emprego. Mesmo com essa vantagem, a empresa de vínculo não ofereceu nova função e ele fez o curso escolhido de Técnico em Meio Ambiente. O Sujeito 7 (S7) exercia a função de serviço geral rural, mas trabalhou por 28 anos como marceneiro; sofreu uma fratura do fêmur devido a um acidente de moto, a empresa de vínculo náo foi localizada e ele realizou o curso escolhido por ele, Operador de Colhedora de Cana. O Sujeito 8 (S8), ajudante externo, fazia carga e descarga de móveis e eletrodomésticos; teve uma dorsalgia devido ao trabalho, mas o nexo causal não foi reconhecido pelo INSS. A empresa o treinou na função de auxiliar administrativo de vendas e ele cursou Informática Básica, pago pelo INSS, e foi considerado reabilitado e apto para exercer a nova função.

\section{A contribuiçáo do PRP na conquista de um emprego e o tempo de afastamento do trabalbo}

Três entrevistados ( $\mathrm{S} 1, \mathrm{~S} 5$ e S8) apontaram que o PRP teve uma contribuição positiva para a conquista de um emprego, quatro (S2, S3, S6 e S7) avaliaram negativamente esse aspecto e um (S4) não atribui essa responsabilidade de reinserção no mercado de trabalho ao Programa, mas a si mesmo. Todos tiveram dificuldade em articular uma resposta com uma justificativa plausível e esclarecedora sobre o tema. A 
maioria dos entrevistados (S2, S4, S6, S7 e S8) apontou a necessidade de articulação entre o PRP do INSS e as empresas, para que os reabilitados sejam encaminhados para um estágio, ou mesmo para uma vaga de emprego.

Sobre o tempo de afastamento do trabalho, os Sujeitos 1, 2, 3, 4, 6 e 8 acreditam que teve influência no retorno ao trabalho. Para $S 1$, os cinco anos em que ficou afastado do trabalho fizeram com que perdesse boa parte de sua juventude, momento em que poderia estar se qualificando ou galgando cargos mais altos em uma empresa. S2, S4 e S8 apontam que as empresas os rejeitam, dado o adoecimento, o processo de afastamento pelo INSS e de reabilitação profissional, além de acharem (as empresas) que isso levaria a um desempenho insatisfatório no serviço. Já S5 e S7 discordaram dos demais, pois apontaram que esse tempo afastado náo influenciou no seu retorno ao trabalho. S5 disse que durante afastamento fez cursos de capacitação e alguns "bicos" para não ficar parado, ou seja, acreditava que uma pessoa ativa na busca por qualificação náo teria dificuldades em retornar ao mercado.

\section{A contribuiçáo dos recursos utilizados no processo reabilitatório e a busca por emprego}

Os cursos, técnicos, cursados por S4 e S6, ou de qualificação, realizados por S3 e S7, denominados por eles como "diploma", não lhes garantiram emprego, pois, para eles, o fato de terem uma limitação funcional, do curso ser numa área nova e de não existir um aprendizado prático num prazo viável daria poucas chances de empregabilidade. A prótese promoveu independência ao trabalhador para o desempenho de uma atividade profissional, mas não significou garantia de emprego. Os sujeitos $S 1$ e $S 5$, que receberam prótese, elogiaram sua qualidade, apesar de criticarem a demora na entrega. S2 e S8, que realizaram treinamento na empresa, pontuaram-no como ineficaz para o aprendizado de uma nova profissão e também na garantia de emprego, uma vez que eles não permaneceram na função acordada com o INSS e foram demitidos poucos meses após o seu retorno ao trabalho.

Sobre a busca por emprego, os sujeitos protetizados, S1 e S5, não apresentaram dificuldades após o desligamento do PRP. S1 encontrou uma vaga por meio de sua rede de contatos e tinha dois empregos como auxiliar administrativo, na época da entrevista; S5, que tinha uma excelente qualificação e poderia retornar para a função de origem assumiu uma vaga logo após ser reabilitada. Os reabilitados por meio do treinamento na empresa de vínculo, S2 e S8, apontaram que, antes do afastamento do trabalho, não tinham dificuldades em encontrar um emprego, porém, após adoecerem, vivenciaram a ausência de oportunidades no mercado. Os que fizeram cursos de qualificação, S3 e S7, tiveram dificuldades, desde o primeiro momento, para enfrentar o mercado de trabalho. Estavam vivendo de "bicos", no mercado informal e, para um deles, na área para a qual foi capacitado, tendo o outro se visto obrigado a exercer a profissão de origem, mesmo sem condiçôes de saúde satisfatórias.

Aqueles que concluíram curso técnico, S4 e S6, estavam empregados, sendo o primeiro na área para a qual fez o curso e o segundo em outra área. S4 apontou que, com a conclusáo do curso, ficou desempregada por quase um ano até conseguir emprego na área para a qual foi reabilitada, onde permanecia, apesar do afastamento temporário 
na ocasião da entrevista. S6 relatou já ter tido dificuldades em conseguir emprego durante sua vida laborativa, acreditando ser porque, na época, tinha baixa escolaridade. Náo foi recolocado pela empresa em função compatível com o curso técnico que fez, mas permanecia nessa empresa em outra área, enfatizando a necessidade de o INSS intervir junto às empresas. Sobre a utilização de vagas especiais, reservadas às pessoas com deficiência ou reabilitadas, apenas $\mathrm{S} 1$ e S5, que apresentavam uma deficiência física, ocupavam essas vagas em suas empresas de vínculo.

\section{Discussáo}

\section{Achados a partir dos resultados dos prontuários}

Foi constatada, no estudo, a predominância de homens no PRP, o que corrobora dados de outras pesquisas, retratando uma desigualdade social e de poder entre os gêneros, encontrada no mundo do trabalho. Possivelmente, os homens têm um acesso mais facilitado ao mercado de trabalho formal e, por outro lado, exista uma tendência de maior adoecimento ou acidente na população do sexo masculino, que usualmente desenvolve atividades que demandam maior carga e desgaste físicos (Takahashi \& Canesqui, 2003). A maioria é composta por adultos jovens, está em sua fase de vida mais produtiva, com uma maior exposição a condiçóes laborativas adversas, que podem levar ao acometimento de alguma doença ou acidente de trabalho. Adoecer ou se acidentar nessa fase da vida reflete que as condiçóes de vida e de trabalho, no Brasil, são causas de incapacidades que não são "[...] apenas resultantes do processo de envelhecimento natural da população” (Takahashi \& Canesqui, 2003; Takahashi et al., 2010).

A baixa escolaridade encontrada é um obstáculo na adaptação do trabalhador à modernização dos postos de trabalho, que exigem qualificação, assim, o baixo nível escolar pode acarretar a perda do emprego após o acidente ou doença. Ainda, as pessoas com escolaridade reduzida comumente se submetem a profissóes menos especializadas, o que pode levar à maior exposição a cargas ergonômicas e ao adoecimento do trabalhador (Gurgel, 2003; Abreu \& Ribeiro, 2010). As profissôes desempenhadas pelos trabalhadores encaminhados ao PRP requerem capacidade física e força corporal; no geral, não exigem escolaridade elevada e maiores competências intelectuais. Esse contingente profissional está mais sujeito a acidentes e a adoecimentos, já que a realização dessas atividades demanda posições ergonômicas desgastantes, esforços intensos, cargas de trabalho repetitivas e exaustivas.

O público em geral do INSS é de pessoas empregadas, conforme verificado nos dados advindos dos prontuários, basicamente em empresas privadas, que têm uma contribuição obrigatória ao INSS. A incidência significativa de pessoas desempregadas indica que a Previdência Social é uma fonte importante de redistribuição de renda, buscada pelo trabalhador adoecido, que pode ver nos benefícios previdenciários um meio de manutenção enquanto estão desempregados (Soares, 1991; Fleury, 1994). O valor do benefício recebido por esse público é muito baixo, sendo os trabalhadores mais 
pobres os que exercem as ocupaçóes de maior risco e estão sujeitos ao perigo de acidentes (Gurgel, 2003).

Quanto maior o tempo que o trabalhador permanecer em benefício, afastado do trabalho, sem estar integrado ao PRP, maior será a dificuldade em retornar ao trabalho (Vacaro \& Pedroso, 2011), assim, entende-se que o encaminhamento precoce, logo após a estabilização do quadro patogênico, pode ser um fator importante no sucesso do retorno ao trabalho.

Os diagnósticos encontrados com maior incidência correspondentes aos códigos $\mathrm{S}$ e $\mathrm{T}$ do CID 10, no geral, referem-se a fraturas, luxações, traumatismos, amputaçôes, ferimentos e esmagamentos de partes do corpo, além de queimaduras, intoxicação, sequelas diversas. Estão relacionados, principalmente, conforme descrito nos laudos, a acidentes de trânsito, muito comuns, a acidentes de trabalho e a acidentes domésticos.

$O$ código $M$, que teve a segunda maior incidência, diz respeito a artrites, artroses, artropatias, coxartrose, gonartrose, espondilopatias, dorsalgias, sinovites e tenossinovites, dentre outros, que envolvem as lesôes por esforços repetitivos (LER) e/ou distúrbios osteomusculares relacionados ao trabalho (Dort). Apesar de poucos serem reconhecidos como adquiridos no trabalho, comumente estáo relacionados às atividades profissionais, que demandam maior exposição a riscos ergonômicos e carga física intensa. Já o código G, no caso do PRP estudado, abrange as pessoas com epilepsia e hemiplegia. Nota-se, na literatura, que as LER/Dort têm uma alta prevalência nos afastamentos do trabalho, mesmo com o aumento de ações preventivas e de fiscalização do trabalho (Ziliotto \& Berti, 2013).

Verificou-se que boa parte dos trabalhadores encaminhados não entrou no Programa e ainda ficou sujeita à avaliação do potencial laborativo realizada pela equipe, que se baseia num formulário previdenciário, com itens pontuados pelo Estado. De acordo com estudos sobre o tema (Svajger \& Piskur, 2016; Finger et al., 2016), a Classificação Internacional de Funcionalidade, Deficiência e Saúde (CIF) tem sido utilizada amplamente nos últimos anos como referência na reabilitação profissional, e há projetos para enriquecer o modelo com construçóes específicas para a área. O uso da CIF como recurso avaliativo, que altera a ótica da incapacidade para funcionalidade, atende ao recomendado pela Organização Mundial de Saúde (Ziliotto \& Berti, 2013); neste sentido, a utilização dessa ferramenta no PRP do INSS talvez abarcasse a complexidade da avaliaçáo do potencial laboral e a tornasse menos excludente.

Para os trabalhadores elegíveis para o Programa, três tipos de recursos foram utilizados para promover a reabilitação profissional. Nas normas internas do Programa (Instituto Nacional do Seguro Social, 2011), tais recursos não são assim especificados, sendo que não existe uma classificação; a elaboração foi feita pelas autoras com base nos dados advindos dos prontuários. As próteses como recurso têm como principal obstáculo para acessá-las, além da necessidade de contribuição anterior ao sistema, a falta de conhecimento em torno desse benefício e a demora na compra e entrega do material. $\mathrm{O}$ processo de compra das próteses, que chega a durar um ano ou mais, vai ao encontro dos achados na pesquisa de Farias (2013), que indicou 16,9 meses de espera, demora 
que estaria associada às demandas burocráticas para tanto e que acarreta um aumento relevante no tempo de permanência no PRP.

Sobre os cursos, em tese, existe a possibilidade do usuário escolher o curso com o qual mais se identifique, mas, na prática, está limitada pela oferta daqueles disponibilizados pelas instituiçóes conveniadas e pela comunidade, ou seja, relaciona-se a fatores externos, alheios à sua vontade. Segundo Bernardo (2006), a oferta é restrita; os reabilitandos sentem dificuldades de enquadrarem sua escolha no catálogo disponível e apontam que a decisão final acaba não sendo deles. Mesmo realizando um curso, em quase todos os casos, ele é feito em uma área nova para o trabalhador, na qual ele não tem experiência. Desse modo, o reabilitado seria um iniciante na profissão para o mercado de trabalho.

Quanto ao recurso treinamento, ele está condicionado à disponibilidade da empresa em oferecer troca de função, e verificou-se que quase a metade das empresas, 41,67\%, não ofertou nova função. Os motivos que inviabilizam a readaptação incluem a inexistência de função compatível e de legislação específica que obrigue as empresas a promoverem a troca de função, aliada à falta de um programa próprio para receber os trabalhadores afastados, ao descaso e despreparo para recebê-los. Ademais, várias empresas são de pequeno porte, portanto, desobrigadas de cumprirem o número mínimo de vagas destinadas às pessoas com deficiência ou reabilitadas (Bregalda \& Lopes, 2016; Vacaro \& Pedroso, 2011). Segundo Simonelli et al. (2010), existe uma fragilidade da equipe do PRP em negociar novos postos de trabalho com as empresas, pois há um desconhecimento dos riscos existentes no processo de trabalho, o que resulta numa baixa fixação dos trabalhadores nas novas funçôes propostas. A falta de articulação do INSS com as empresas, em muitos casos, provoca a demissão do reabilitado ou o retorno para a perícia médica, o que tornaria o processo reabilitatório ineficaz. Por um lado, Vacaro \& Pedroso (2011) concluíram que os reabilitados que foram readaptados na empresa de vínculo obtiveram melhores resultados; por outro, Maeno \& Vilela (2010) verificaram que, frequentemente, os funcionários readaptados passam a ser empregados de segunda classe nos locais de trabalho.

Neste estudo, a taxa de empregabilidade dos trabalhadores reabilitados (49,02\%) aparenta ser satisfatória, pois abarcou quase a metade deles. Todavia, o percentual de pessoas empregadas tem como limitaçáo não demonstrar se foi por meio dos recursos disponibilizados no PRP que houve o acesso a uma vaga ou se foi por meio de estratégias individuais. Ainda, estar empregado e ser contribuinte do INSS não significam que a função de vínculo seja adequada ao potencial laboral do trabalhador, ou que seja desempenhada na área para a qual ele foi reabilitado. A taxa de reabilitados "Sem Vínculo", que não são contribuintes do INSS, não se trata necessariamente de "desempregados" ou "sem trabalho", uma vez que podem estar vinculados a outros regimes previdenciários ou mesmo ao mercado de trabalho informal, o que poderia aumentar a taxa de empregabilidade desses ex-usuários do PRP.

A preocupação se o reabilitado foi, ou não, recolocado, se de fato se estabilizou em um emprego, tornaram-se problemas de ordem pessoal e não problemas do Estado e da 
sociedade no Brasil (Soares, 1991). Vacaro \& Pedroso (2011) constataram uma taxa de 29,4\% de retorno ao trabalho das pessoas reabilitadas pelo Programa de uma Agência do INSS, após um ano de conclusão da reabilitação profissional; já o índice de retorno ao trabalho apontado pela literatura internacional demonstra uma taxa entre $40 \%$ a $70 \%$ (Bartilotti et al., 2009; Ahlgren et al., 2007). Em pesquisa realizada na Suécia, que buscou avaliar a eficácia de um programa de reabilitaçáo profissional, a taxa de retorno ao trabalho foi de $41,7 \%$, dois anos após a sua conclusão. Os trabalhadores com maiores chances de retornarem ao trabalho eram jovens, entre 16 a 29 anos, empregados na indústria e com pouco tempo de afastamento (Ahlgren et al., 2007).

Sobre os laudos finais dos prontuários dos trabalhadores que não concluíram o PRP, um dos principais motivos de desligamento do reabilitando, a "Impossibilidade de Retorno ao Trabalho", ocorreu devido ao fato de sua inclusão no PRP representar uma tentativa de readaptação na empresa de vínculo e, quando esta é inviável, a equipe sugeriu a aposentadoria por invalidez. No lado oposto, a "Possibilidade de Retorno ao Trabalho" ocorreu, também com frequência, quando, apesar da impossibilidade de readaptação na empresa, a pessoa ser considerada em condiçóes de trabalhar, pois possuía qualificaçáo profissional ou experiências anteriores compatíveis ou que poderiam retornar à mesma função com adequações.

A equipe também descreveu como motivo frequente para interromper o processo reabilitatório o "Não Cumprimento do Programa", quando o usuário abandona, não inicia, está infrequente, desinteressado, foi reprovado no curso proposto, ou, quando foi considerado inapto pela empresa no treinamento. Nesses casos, o pagamento do benefício foi suspenso, atendendo às normas internas, já que isso é avaliado como "recusa passiva" ao PRP (Brasil, 2010). Trata-se de uma situaçáo bastante delicada e difícil, tanto para o trabalhador quanto para a equipe. O bloqueio do pagamento pode implicar dificuldades financeiras sérias para o trabalhador, além de expor o servidor responsável pelo caso, que é quem emite o documento solicitando o bloqueio e informa ao usuário sobre a decisão. Bernardo (2006) pontua que todo o processo é permeado pelo recebimento do benefício, na maioria das vezes, fonte de renda principal do trabalhador, ou única fonte de seu sustento e de sua família.

Pôde-se verificar que as normas do PRP, a conduta dos técnicos nos atendimentos e a linguagem usada nos laudos se voltam para "impor" ao trabalhador elegível a realização do PRP, sem o seu efetivo envolvimento nas decisôes que permeiam o processo. Em outra perspectiva, a reabilitação profissional poderia se transformar em um benefício, e não se manter numa lógica autoritária e, contraditoriamente, punitiva, na qual o trabalhador se "submete" e "cumpre" a reabilitação, condição necessária para o recebimento do benefício previdenciário (Brasil, 2010). Os trabalhadores, elos mais frágeis no processo produtivo capitalista, frente a um mercado de trabalho cada vez mais competitivo, excludente e flexível, que deixa à deriva inúmeras pessoas que não alcançam o padrão imposto, necessitam da intermediação do Estado nos conflitos e nas contradiçốes existentes entre eles (Castel, 2010; Maeno et al., 2009). 


\section{Achados tomando-se os resultados das entrevistas}

Cada entrevistado trazia uma história peculiar e seguiu um percurso diferente no PRP, mas os sujeitos tinham em comum o fato de estarem afastados do trabalho, recebendo o benefício previdenciário. Eles apontaram dificuldades em disputarem uma vaga no mercado de trabalho formal e que o PRP não contribuiu efetivamente para a conquista de um emprego, ou seja, cessar a responsabilidade do poder público para com esse trabalhador que ficou com sequelas incapacitantes no ato da emissão do certificado do PRP não promove a reinserçáo laboral. Ainda, os entrevistados mostraram que nenhum dos recursos utilizados proporcionou o aprendizado de uma profissão. Todavia, apesar das críticas diversas ao PRP e da maioria não estabelecer uma relação direta entre ele e sua reinserção no mercado de trabalho, quando se questionou sobre a opinião deles referente ao mesmo Programa e sobre a influência dos recursos utilizados no processo reabilitatório, observou-se que estes tinham um significado em suas vidas e foram importantes no momento do retorno. A associação feita não era direta, mas à medida que era exposta a importância do curso e da prótese nas suas vidas laborativas, ficava claro que foram meios para o trabalhador poder conquistar, senão um emprego, ao menos um reconhecimento pessoal e profissional no mercado.

Ao poder público "[...] cabe sempre o papel de tomar o seu devido lugar de guardião das leis e de regulador legal e social em benefício do exercício da cidadania” (Maeno et al., 2009, p. 58). É necessário que a Previdência Social “[...] incorpore no seu conceito de excelência o seu caráter, de fato, público", com diretrizes claras na execução de políticas públicas e ampla participação da sociedade nas decisões (Maeno \& Vilela, 2010, p. 96). O Estado se recusa explicitamente a garantir trabalho para cada um, e para os empregadores permanece sendo vantagem agir como se o livre acesso ao trabalho fosse o mesmo que o direito ao trabalho. O desemprego "[...] é seguramente, hoje, o risco social mais grave, o que tem os efeitos desestabilizadores e dessocializantes mais desastrosos para os que o sofre" (Castel, 2010, p. 584).

Apesar de existir a Lei de Cotas, que garante vagas especiais, reservadas às pessoas com deficiência ou reabilitadas pelo INSS, não existem outras leis nem mesmo incentivos fiscais que possibilitem às empresas investirem na adequação dos postos de trabalho para receber esse perfil de trabalhador. Segundo Gurgel (2003), não há fiscalização adequada para que seja cumprida a lei; ademais, o valor da multa é considerado irrisório para muitas empresas, que optam por pagá-la quando são autuadas. $\mathrm{O}$ mercado de trabalho tende a discriminar aqueles que possuem uma limitação funcional. Cultua-se o corpo humano como uma máquina saudável, produtiva, dentro dos padróes de eficiência; as pessoas acidentadas e adoecidas, que apresentam uma limitação, sofrem por serem diferentes e têm dificuldades de acesso ao mercado de trabalho. Os empregadores demonstram dúvidas quando consideram a contratação de uma pessoa com deficiência (Gurgel, 2003; Farias, 2013).

Promover a melhoria das condiçôes de escolarização e de formação de uma população, cuja ausência de qualificação, mais do que a falta do trabalho, torna-a não empregável, representa uma possibilidade de, pelo menos, igualá-la ao mesmo nível das oportunidades que poderão ser abertas. Essas são condiçôes necessárias, 
mas não suficientes. A elevação do nível de formação deve continuar sendo um objetivo social, contudo, nem todo mundo é qualificado e competente. É preciso considerar, como um problema, a possível não empregabilidade das pessoas qualificadas (Castel, 2010).

Nota-se que a maioria dos trabalhadores entrevistados apontou que adoecer e ficar afastado do trabalho, principalmente por um longo período, pode enfraquecer suas estratégias de defesa frente às adversidades trazidas pela nova realidade. Conforme Vacaro \& Pedroso (2011), o tempo de permanência no Programa se mostra inversamente proporcional ao sucesso no retorno do reabilitado ao trabalho; quanto mais tempo em benefício, mais encontra dificuldade em conquistar uma vaga. $O$ processo de trabalho se converteu em um meio de subsistência, assim, a força de trabalho se equipara a uma mercadoria, cujo objetivo é a produção de mercadorias; "[...] o que deveria ser a forma humana de realização do indivíduo reduz-se à única possibilidade de subsistência do despossuído" (Antunes, 2011, p. 145). Há uma desrealização social do trabalhador, que passa a repudiar o trabalho, pois não se satisfaz com ele, mas, ao contrário, degrada-se; não mais se reconhece, nega-se (Antunes, 2011).

\section{Conclusóes}

Acredita-se que este estudo produziu resultados que refletem o perfil de pessoas que são atendidas no Programa de Reabilitação Profissional das demais Agências da Previdência Social da região Sudeste do Brasil, a região de maior relevância econômica do Brasil (Instituto Brasileiro de Geografia e Estatística, 2014). Das 592 pessoas encaminhadas para o PRP, um pouco menos da metade foi elegível, ou seja, o Programa segue uma lógica excludente, nos moldes de um seguro privado, que visa a diminuir custos e não à concessão de benefícios. $\mathrm{O}$ acesso dos trabalhadores ao direito de participarem do PRP é restrito, permeado por avaliaçóes periciais que não os consideram como sujeitos ativos do processo reabilitatório. A reabilitação profissional é um direito que, na prática, não foi consolidado como um aliado do trabalhador brasileiro. Se eleito para o Programa, boa parte náo conclui o processo, e aqueles que o fazem nem sempre alcançam um emprego digno. Apesar dos obstáculos, os reabilitados tiveram uma taxa aparente de sucesso na conquista de uma vaga de emprego, de 49,02\%. Considerandose que o Brasil é um país que permanece com problemas do subdesenvolvimento, com uma alta taxa de desigualdade, desemprego e concentração de renda, o índice de empregabilidade dos reabilitados se mostra satisfatório e motivador, se comparado ao de outros estudos (Bartilotti et al., 2009; Ahlgren et al., 2007) de países desenvolvidos, com sociedades mais igualitárias, democráticas e que prezam pelo bem-estar social.

Os depoimentos dos reabilitados apresentam pontos fundamentais que podem servir de subsídios para a melhoria do PRP. Ressalta-se a necessidade de articulaçáo com as demais políticas de amparo ao trabalhador para promover açôes intersetoriais, com entidades públicas e privadas, sociedade civil, que levem a garantir uma vaga de estágio e/ou emprego na área para a qual os sujeitos foram reabilitados. Também é fundamental a mobilizaçáo dos profissionais que realizam os atendimentos, uma vez que eles podem 
colaborar no processo de fiscalização das condições de trabalho, do cumprimento da legislação, e, em última análise, na prevenção de riscos nos ambientes de trabalho. Isto, se o objetivo for, de fato, proporcionar um atendimento mais rico e efetivo, que abarque as reais necessidades do trabalhador e as complexidades provenientes do processo de retorno ao trabalho.

\section{Agradecimentos}

Ao Programa de Pós-Graduação em Terapia Ocupacional da Universidade Federal de São Carlos, que viabilizou a versão em inglês deste artigo.

\section{Referências}

Abreu, A. T. J. B., \& Ribeiro, C. A. B. (2010). Prevalência de lombalgia em trabalhadores submetidos ao Programa de Reabilitação Profissional do Instituto Nacional do Seguro Social (INSS). Acta Fisiátrica, $17(4), 148-152$.

Ahlgren, A., Bergtoth, A., Ekhokm, J., \& Schüldt, K. (2007). Work resumption after vocational rehabilitation: a follow-up two years after completed rehabilitation. Work, 28(4), 343-354.

Antunes, R. (2011). Adeus ao trabalho? Ensaio sobre as metamorfoses e a centralidade no mundo do trabalho. São Paulo: Cortez.

Bartilotti, C. B., Andrade, P. R., Varandas, J. M., Ferreira, P. C. G., \& Cabral, C. (2009). Programa de Reabilitação Ampliada (PRA): uma abordagem multidimensional do processo de reabilitação profissional. Acta Fisiátrica, 16(2), 66-75.

Batich, M. (2004). Previdência do trabalhador: uma trajetória inesperada. São Paulo em Perspectiva, 18(3), $33-40$.

Bernardo, L. D. (2006). Os significados do trabalho e da reabilitação profissional para o trabalhador incapacitado para o exercício da profissão habitual (Dissertação de mestrado). Faculdade de Medicina, Universidade Federal de Minas Gerais, Belo Horizonte.

Brasil. (1991). Lei no 8.213, de 24 de julho de 1991. Dispóe sobre os Planos de Benefícios da Previdência Social e dá outras providências. Diário Oficial [da] República Federativa do Brasil, Brasília, seção 1, p. 14809 .

Brasil. (2010). Decreto no 3.048, de 06 de maio de 1999. Capítulo V: da habilitação e da reabilitação profissional. Diário Oficial [da] República Federativa do Brasil, Brasília.

Brasil. (2018). Manual Técnico de Procedimentos da Área de Reabilitação Profissional. Brasília: INSS.

Brasil. (2014). Classificação nacional de atividades econômicas. Recuperado em 1 de agosto de 2014, de http://subcomissaocnae.fazenda.pr.gov.br/modules/conteudo/conteudo.php?conteudo=1

Bregalda, M. M., \& Lopes, R. E. (2016). A reabilitação profissional no INSS: caminhos da terapia ocupacional. Saúde e Sociedade, 25(2), 479-493.

Castel, R. (2010). As metamorfoses da questão social: uma crônica do salário. Petrópolis: Vozes.

Farias, S. H. (2013). Estudo dos trabalhadores vitimas de acidentes de trabalho grave participantes do Programa de Reabilitação Profissional do Instituto Nacional de Seguridade Social de Campinas, usuários de órtese e prótese (Dissertação de mestrado). Faculdade de Ciências Médicas, Universidade Estadual de Campinas, Campinas. 
Finger, M., De Bie, R., Selb, M., \& Escorpizo, R. (2016). An examination of concepts in vocational rehabilitation that could not be linked to the ICF based on an analysis of secondary data. Work, 53(4), 775-792.

Fleury, S. (1994). Estado sem cidadãos: seguridade social na América Latina. Rio de Janeiro: FIOCRUZ.

Gurgel, M. E. P. (2003). A reabilitação profissional: um programa de reinserção do acidentado no mercado de trabalho (Dissertação de mestrado). Universidade Federal de Pernambuco, Recife.

Instituto Brasileiro de Geografia e Estatística - IBGE. (2014). Cidades. Recuperado em 3 de novembro de 2014, de http://www.ibge.gov.br

Instituto Nacional do Seguro Social - INSS. (2011). Despacho Decisório No2/DIRSAT/INSS, 24 novembro de 2011. Manual técnico de procedimentos da área de reabilitação profissional. Brasília: INSS.

Lakatos, E. M., \& Marconi, M. A. (2002). Técnicas de pesquisa. São Paulo: Atlas.

Maeno, M., \& Vilela, R. A. G. (2010). Reabilitação profissional no Brasil: elementos para a construção de uma política pública. Revista Brasileira de Saúde Ocupacional, 35(121), 87-99.

Maeno, M., Takahashi, M. A. C., \& Lima, M. A. G. (2009). Reabilitação Profissional como política de inclusão social. Acta Fisiátrica, 16(2), 53-58.

Sampieri, R. H., Collado, C. F., \& Lucio, M. P. B. (2006). Metodologia de pesquisa. São Paulo: McGraw Hill.

Santos, G. S. H., \& Lopes, R. E. (2015). A (in)elegibilidade de trabalhadores encaminhados ao Programa de Reabilitação Profissional do INSS. Revista Katálysis, 18(2), 151-161.

Simonelli, A. P., Camarotto, J. A., Bravo, E. S., \& Vilela, R. A. G. (2010). Proposta de articulação entre abordagens metodológicas para melhoria do processo de reabilitação profissional. Revista Brasileira de Saúde Ocupacional, 35(121), 64-73.

Soares, L. B. T. (1991). Terapia ocupacional: lógica do capital ou do trabalho. São Paulo: Hucitec.

Soares, L. T. (2001). Ajuste neoliberal e desajuste social na América Latina. Rio de Janeiro: Vozes.

Svajger, A., \& Piskur, B. (2016). The clinical utility of the Canadian Occupational Performance Measure in vocational rehabilitation: a qualitative study among occupational therapists in Slovenia. Work, 54(1), 223-233.

Takahashi, M. A. B. C., \& Iguti, A. M. (2008). As mudanças nas práticas de reabilitação profissional da previdência social no Brasil: modernização ou enfraquecimento da proteção Social? Cadernos de Saúde Pública, 24(11), 2661-2670.

Takahashi, M. A. C., \& Canesqui, A. M. (2003). Pesquisa avaliativa em reabilitação profissional: a efetividade de um serviço em desconstrução. Cadernos de Saúde Pública, 19(5), 1473-1483.

Takahashi, M., Kato, M., \& Leite, R. A. O. (2010). Incapacidade, reabilitação profissional e saúde do trabalhador: velhas questóes, novas abordagens. Revista Brasileira de Saúde Ocupacional, 35(121), 7 9.

Vacaro, J. E., \& Pedroso, F. S. (2011). Desempenho dos segurados no serviço de reabilitação do Instituto Nacional de Seguridade Social. Acta Fisiátrica, 18(4), 200-205.

Yazbek, M. C. (2012). Pobreza no Brasil contemporâneo e formas de seu enfrentamento. Serviço Social đ Sociedade, (110), 288-322. http://dx.doi.org/10.1590/S0101-66282012000200005.

Ziliotto, D. M., \& Berti, A. R. (2013). Reabilitação profissional para trabalhadores com deficiência: reflexóes a partir do estado da arte. Saúde e Sociedade, 22(3), 736-750. 


\section{Contribuiçáo dos Autores}

Geovana de Souza Henrique dos Santos, sob orientação de Roseli Esquerdo Lopes, realizou a pesquisa da qual decorre este texto. Ambas contribuíram na concepção, redação e revisão do texto e aprovaram a sua versão final.

\section{Fonte de Financiamento}

Coordenação de Aperfeiçoamento de Pessoal de Nível Superior - CAPES - Código 001.

\section{Autor para correspondência}

Geovana de Souza Henrique dos Santos

e-mail: geovana_shs@yahoo.com.br

\section{Editora de seçáo}

Profa. Dra. Ana Paula Malfitano 